\title{
A PRÁTICA PLURALISTA NA FORMAC̣ÃO INICIAL DE PROFESSORES DE FÍSICA
}

\author{
Ricardo Francisco Pereira* \\ Polônia Altoé Fusinato** \\ Dulcinéia Ester Pagani Gianotto***
}

RESUMO: O presente trabalho tem como objetivo mostrar que uma formação inicial baseada na prática pluralista e em atividades que envolvem a prática reflexiva, o lúdico e o uso de tecnologias pode contribuir para uma melhor capacitação de professores de Física visando combater vários dos problemas enfrentados pelos docentes em sala de aula. A pesquisa foi realizada sob uma perspectiva qualitativa e procura responder questões particulares da realidade investigada, preocupada com o diagnóstico do problema em um determinado contexto específico. A metodologia de pesquisa escolhida para análise dos dados é a Análise de Conteúdo proposta por Bardin. Como resultado, verificamos uma evolução gradativa dos licenciandos ao assumirem uma postura participativa, reflexiva e interativa durante as atividades desenvolvidas, indicando que a proposta tem potencial para promover a formação inicial de professores de Física, no sentido de contribuir significativamente para que esses profissionais em formação adquiram reflexibilidade, dinamicidade e experiências diversificadas.

Palavras-chave: Formação inicial de professores. Estágio Supervisionado em Física. Ensino de Física.

\section{LA PRÁCTICA PLURALISTA EN LA FORMACIÓN DEL PROFESOR DE FÍSICA}

RESUMEN: El presente trabajo tiene como objetivo mostrar que una formación inicial basada en la práctica pluralista y en actividades que involucren la práctica reflexiva, el lúdico y el uso de tecnologías puede contribuir a una mejor capacitación de profesores de Física con la intención de combatir varios de los problemas enfrentados por los docentes en clase. La investigación se realizó desde una perspectiva cualitativa y busca contestar cuestiones particulares de la realidad investigada, preocupada por el diagnóstico del problema en un determinado contexto específico. La metodología de investigación elegida para el análisis de los datos es el Análisis de Contenido propuesto por Bardin. Como resultado, verificamos una evolución gradual de los estudiantes de la licenciatura cuando asumen una postura participativa, reflexiva e interactiva a lo largo de las actividades desarrolladas; eso indica que la propuesta tiene potencial para promover la formación inicial de los profesores de Física, lo que

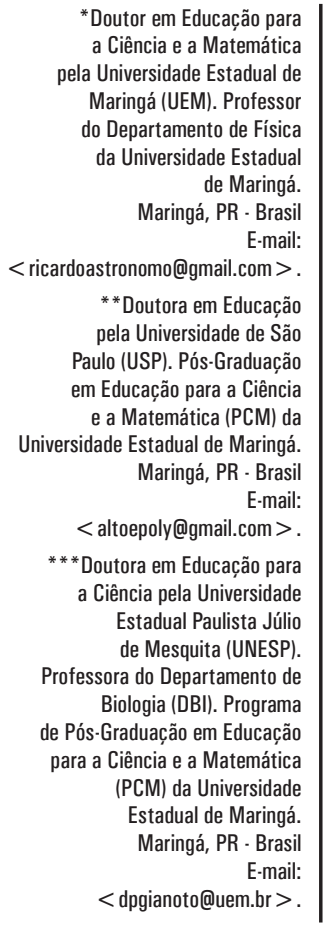

*Doutor em Educação para Ciência e a Matemática

Maringá (UEM). Professor

do Departamento de Física da Universidade Estadual de Maringá E-mail: < ricardoastronomo@gmail.com>.

* *Doutora em Educação pela Universidade de São USP). Pos-Graduação Educaçáco (PCM) da Matemática (PCM) da Maringá, PR - Brasil E-mail:

< altoepoly@gmail.com>

Ciência pela Universidade Estadual Paulista Júlio de Mesquita (UNESP). Biologia (DBI). Programa de Pós-Graduação em Educação Ciência e a Matemática Estadual de Maringá. Maringá, PR - Brasil E-mail: 
contribuye significativamente a que eses profesionales en formación adquieran reflexibilidad, dinamicidad y experiencias diversificadas.

Palabras-clave: Formación inicial de profesores. Prácticas Supervisadas en Física. Enseñanza de Física.

\section{INITIAL TEACHER EDUCATION: ANALYSIS OF SOME ACTIVITIES PROPOSED FOR A DISCIPLINE SUPERVISED TRAINING IN PHYSICS}

ABSTRACT: This paper aims to show that a pluralistic practice-based activity that involves the reflective practice, the playful and the use of technology can contribute to a better initial training of Physics teachers and help them to face several classroom problems. The survey was conducted under a qualitative perspective and seeks to answer particular questions about the investigated reality, concerned with the diagnosis of the problem at a specific context. For data analysis, we have chosen the Content Analysis proposed by Bardin as research methodology. As a result, we have verified a gradual evolution of undergraduates by taking a participatory, reflective and interactive posture during the activities, showing that the proposal has the potential to promote initial training of Physics teachers, in the sense of contributing significantly so that these new professionals to acquire reflexivity, dynamicity and diversified experiences.

Keywords: Initial teacher education. Teacher profile. Supervised training. Physics education. 


\section{INTRODUÇÃO}

No discurso das políticas públicas sobre a educação, é possível perceber a ideia de que a educação serviria de veículo para uma transformação social e econômica (MCLAREN, 1999). Neste sentido, a melhoria da qualidade do ensino de Física passa também pela definição de uma nova postura didático-pedagógica do professor.

Entendemos que há uma necessidade de intervenção na formação inicial, não somente no aspecto pedagógico, mas também em relação às atitudes dos licenciandos para com a profissão. Precisamos de um novo perfil de professor que atue na sala de aula interagindo, gerando interesse e participação dos alunos com relação ao conteúdo abordado. Para que isso possa acontecer, um dos pontos chaves é a capacidade de reflexão do professor sobre a sua prática, para que seja possível viabilizar novas perspectivas para a sua evolução como docente. A noção de pensamento reflexivo na educação surge no Brasil, na década de 1990, sendo difundido principalmente nos trabalhos de Donald Schön (1992), Kenneth Zeichner (1993) e Antônio Nóvoa (1992), voltados para a área de formação de professores.

Este trabalho é parte do resultado de uma pesquisa realizada para a obtenção do título de doutorado, onde a proposta foi investigar as contribuições que algumas ações e atividades trabalhadas com licenciandos da disciplina Estágio Supervisionado em Física II, do curso de Licenciatura em Física da Universidade Estadual de Maringá (UEM) no ano de 2012, poderiam gerar para proporcionar uma formação pluralista do professor de Física. O que se pretende é a formação de um professor com um perfil dinâmico e interativo, estimulado a produzir e usar diversos recursos de ensino na sala de aula, sempre refletindo sobre sua atuação e os resultados de sua prática.

\section{REFERENCIAL TEÓRICO}

Há várias pesquisas indicando problemas nas disciplinas pedagógicas dos cursos de Licenciatura em Física, tal como a desarticulação entre as disciplinas (teoria e prática), os quais acabam por propiciar uma formação inicial abaixo da média (CAMARGO; NARDI, 2006; ARAÚJO, 2009; BARCELLOS; KAWAMURA, 2009; LEODORO; TEDESCHI, 2009; RAMOS; BENETTI, 2009; CAMARGO et al., 2012). Como a formação inicial é a base de todo o conhecimento dos docentes sobre a Física e sobre como trabalhar com recursos e metodologias, uma formação ruim prejudica a capacidade dos professores em saber lidar com os problemas de sala de aula.

Ainda, relacionado a esses problemas, podemos incluir a estrutura pedagógica dos cursos como um fator relevante para essa dissociação entre a formação científica e a formação pedagógica. Abib (2002) destaca que

(...) a organização curricular tradicional ainda presente na grande maioria dos cursos de Licenciatura das universidades brasileiras pressupõe que, após a "aquisição" dos conhecimentos teóricos fundamentais, a prática, vista como uma aplicação destes, garantiria o aprender a ensinar (p.188). 
Isso é importante porque a principal consequência é a "pequena (ou nenhuma) utilização de propostas de ensino veiculadas nesse tipo de disciplina pelos professores iniciantes, quando ingressam efetivamente em seu trabalho docente (ABIB, 2002, p.189)". Para a autora, grande parte desse problema pode ser atribuída à inadequação dos programas de formação de professores, pois nesses há um

(...) enorme distanciamento entre o que é proposto pelos "especialistas" e o que efetivamente é viável para os professores, dadas as suas condições efetivas de conhecimentos, habilidades e aos contextos escolares nos quais atuam. Um dos aspectos desse distanciamento reside no pressuposto dos programas tradicionais de formação de professores que se voltariam para a formação mais de técnicos do que de educadores, implícita na relação subjacente à maneira usual de ensino dos futuros professores, que se caracteriza pelos que produzem os conhecimentos sobre o ensino e os que aplicam (ou poderiam aplicar) nas escolas (ABIB, 2002, p.189-190).

O professor em formação precisa entender que a docência é um processo dinâmico, vivencial e muito mais complexo do que um simples treinamento para a docência. A formação inicial é o ponto de partida, mas o final do curso não é o término da formação. A maior parte da experiência adquirida pelo professor vem da sua vivência em sala de aula.

Abib (1996), em estudo sobre a formação de professores, aponta três grandes problemas:

1) Desarticulação entre a teoria e a prática;

2) Falta de articulação entre a universidade e as escolas de ensino fundamental e médio;

3) A desvalorização profissional do professor e dos cursos de licenciatura (ABIB, 1996 apud CAMARGO; NARDI, 2006, p.5).

Complementando esses três grandes problemas, Camargo e Nardi (2006), refletindo sobre a opinião de Abib (1996), indicam algumas consequências para o profissional formado sob a égide desses problemas:

a) reproduz a desarticulação, as práticas vivenciadas e os valores predominantes em sua formação (CUNHA, 1989; PAGOTTO, 1989; CARVALHO e GIL, 1993);

b) apresenta uma prática em sala de aula centrada em mecanismos de transmissão/recepção/ fixação de um conteúdo "pronto" pretensamente neutro, verdadeiro e desvinculado das necessidades da formação de um cidadão crítico e participante de seu meio (DEMO, 1992; TANCREDI, 1995; LIMA e outros, 1995);

c) apresenta uma postura de desesperança e resistência (FRANCHI, 1995);

d) apresenta uma postura pouco crítica em relação às características e à importância de seu papel político (ALMEIDA, 1986; MENEZES, 1987; FERNANDES, 1987); 
e) veicula um ensino caracterizado predominantemente por uma abordagem tradicional definida pela função de transmissão pelo professor de um conteúdo que se constitui o próprio fim da existência escolar (MIZUKAMI, 1983, 1986) (CAMARGO; NARDI, p. $5,2006)$.

Essas consequências acabam marcando a vida profissional do professor e, mais ainda, refletindo-se na visão que os alunos do Ensino Médio acabam tendo sobre a Física.

Uma formação mais coerente com as necessidades atuais precisa favorecer uma atuação crítica, reflexiva e a socialização do conhecimento. Segundo os PCN,

(...) além de uma formação inicial consistente, é preciso considerar um investimento educativo contínuo e sistemático para que o professor se desenvolva como profissional de educação. O conteúdo e a metodologia para essa formação precisam ser revistos para que haja possibilidade de melhoria do ensino. A formação não pode ser tratada como um acúmulo de cursos e técnicas, mas sim como um processo reflexivo e crítico sobre a prática educativa. Investir no desenvolvimento profissional dos professores é também intervir em suas reais condições de trabalho (BRASIL, p. 25, 1997).

Corroborando os PCNs, Libâneo (2011) também indica essa mudança no perfil dos professores ainda nas universidades:

(...) novas exigências educacionais pedem às universidades um novo professor capaz de ajustar sua didática às novas realidades da sociedade, do conhecimento, do aluno, dos meios de comunicação. O novo professor precisaria, no mínimo, de adquirir sólida cultura geral, capacidade de aprender a aprender, competência para saber agir na sala de aula, habilidades comunicativas, domínio da linguagem informal e dos meios de informação, habilidade de articular as aulas com as mídias e as multimídias (p. 29-30).

O professor precisa conhecer e saber usar também várias metodologias e recursos de ensino (experimentos, tecnologia, vídeos, simulações, animações, jogos, textos, tirinhas, sites, fotografias etc.), diversificando suas aulas e o modo de ensinar. Com isso, ele maximiza as chances de uma aprendizagem efetiva para o grande número de alunos em sala de aula. O contato com essas metodologias e recursos de ensino deve acontecer ainda na formação inicial. Essa é a ideia básica da proposta do Pluralismo Metodológico, que nasce a partir da crítica ao uso de uma só metodologia em sala de aula. Essa prática "mono-metodológica" é criticada porque dificilmente consegue alcançar todos os alunos em sala de aula. Nesse ambiente, cada um com sua experiência única de vida e também forma única de agir e pensar, torna o ensino-aprendizagem extremamente complexo. O objetivo essencial da proposta

(...) não é o de substituir um conjunto de regras por outro conjunto do mesmo tipo, mas argumentar no sentido de que todos os modelos e metodologias, inclusive as mais óbvias, têm vantagens e restrições. A inspiração da abordagem pode ser atribuída diretamente às ideias do pensador Feyerabend (1989). Da mesma forma que esse autor defende uma 
metodologia pluralista para o desenvolvimento científico, denominada de anarquismo epistemológico, paralelamente imaginamos que, em virtude da complexidade das variáveis envolvidas numa sala de aula, o mecanismo de ensino-aprendizagem é capaz de ser convenientemente equacionado quando uma prática instrucional pluralista estiver em jogo (LABURU; ARRUDA; NARDI, 2003, p. 251).

Essa proposta pluralista é a que melhor se enquadra no perfil de metodologia voltada especificamente para a formação pedagógica, na qual transpomos para a formação do professor de Física, que pretendemos alcançar.

A sala de aula é um ambiente dinâmico e mutável, tornando o processo de ensino-aprendizagem altamente complexo e impondo aos professores a necessidade de conhecer e saber utilizar várias metodologias e recursos de ensino que possibilitem alcançar a maior quantidade possível de alunos na sala de aula. Para os autores, “(...) quanto mais variado e rico for o meio intelectual, metodológico ou didático fornecido pelo professor, maiores condições ele terá de desenvolver uma aprendizagem significativa da maioria de seus alunos" (LABURU; ARRUDA; NARDI, 2003, p. 258).

Sabe-se que todas as metodologias ou práticas a disposição dos professores tem suas vantagens e desvantagens, por isso, uma formação pedagógica que priorize o contato dos professores em formação com várias metodologias e recursos dá a esses futuros professores melhores condições de conseguir criar um ambiente verdadeiro de aprendizagem significativa.

\section{CONTEXTO E METODOLOGIA ${ }^{1}$}

A Pesquisa foi realizada com seis alunos do terceiro ano do curso de Licenciatura em Física da UEM, na disciplina de Estágio Supervisionado em Física II, no segundo semestre do ano de 2012. Todos os alunos matriculados na disciplina participaram da pesquisa.

A essência dessa pesquisa é demonstrar que uma abordagem pluralista voltada para o uso e produção de recursos de ensino nas disciplinas de Estágio Supervisionado em Física pode contribuir significativamente para que os professores em formação adquiram reflexibilidade, dinamicidade e experiências diversificadas.

Nosso objetivo consistiu em analisar as atividades que foram propostas na disciplina e as reflexões de um grupo de seis alunos sobre essas atividades e a própria disciplina, optando para isso, pela pesquisa qualitativa. Essa modalidade de pesquisa pode fornecer profundidade suficiente em sua análise, para descobrir as variáveis não mensuráveis que moldam essas opiniões e suas ações. Para Suassuna (2008, p. 348), [... " "a pesquisa qualitativa responde a questões particulares, enfoca um nível de realidade que não pode ser quantificado e trabalha com um universo de múltiplos significados, motivos, aspirações, crenças, valores e atitudes”. [...]

A pesquisa qualitativa, em uma visão geral, é exploratória e estimula os entrevistados a pensarem sobre algum tema, objeto ou conceito. Faz emergir aspectos subjetivos e atingem motivações não explícitas, ou mesmo conscientes, de maneira espontânea. São utilizadas quando se buscam percepções e entendimento sobre a natureza geral de uma questão, abrindo espaço para a interpretação. 
Para a coleta de dados nesta investigação, utilizamos o memorial que todos os licenciandos entregaram ao final do semestre, o qual constituiu uma das avaliações da disciplina. Nesse memorial, cada um descreveu brevemente as atividades executadas, refletindo sobre cada uma delas, avaliando sua importância para a formação e refletindo ainda sobre tudo que julgassem ser relevantes para a discussão.

Escolhemos o memorial como instrumento principal de coleta de dados na pesquisa por acreditar ser ele um recurso a nos oferecer mais informações, e de melhor qualidade, e que também propicia ao licenciando oportunidades de reflexão sobre a vivência prática na disciplina de estágio.

A metodologia escolhida para a análise dos memoriais foi a Análise de Conteúdo proposto por Bardin (2011), aplicando o critério de categorias temáticas. O objetivo desse método de análise é o de identificar unidades de sentidos imersas no texto a ser analisado, para assim, obter indicadores úteis para a pesquisa e, a partir desses indicadores, buscar desvelar as essências que possam trazer à luz o fenômeno sob investigação.

Segundo Bardin (2011), esse tipo de análise envolve três fases, são elas: 1) pré-analise, 2) exploração do material e 3) tratamento dos resultados, inferência e interpretação.

Como o memorial escrito pelos licenciandos, foi a única fonte de dados, a fase inicial (pré-análise) foi mais simplificada por não precisar organizar diferentes fontes de dados.

A segunda fase, a exploração do material, consistiu em identificar trechos considerados importantes. Esses trechos são chamados de unidades de contexto. Os trechos selecionados representam as partes importantes dos discursos de cada sujeito dentro do contexto investigado. Foram selecionados nos memoriais um total de 62 unidades de contexto, separadas no discurso sobre cada atividade executada.

$\mathrm{Na}$ última fase (tratamento dos resultados, inferência e interpretação), as unidades de contexto extraídas foram analisadas à luz dos objetivos da pesquisa e as categorias apresentadas foram predeterminadas a partir do contexto das opiniões dos licenciandos nos seus respectivos memoriais. Como a orientação para a elaboração do memorial indicava que o licenciando precisava refletir sobre a atividade realizada e a importância dela para a sua formação docente, as opiniões foram fortemente ligadas a isso, inviabilizando extrair unidades de registro a partir das unidades de contexto e a criação de categorias a partir das unidades de registro. Conforme Moraes:

A natureza das unidades de análise necessita ser definida pelo pesquisador. As unidades podem ser tanto as palavras, frases, temas ou mesmo os documentos em sua forma integral. Deste modo para a definição das unidades de análise constituintes de um conjunto de dados brutos pode-se manter os documentos ou mensagens em sua forma íntegra ou pode-se dividi-los em unidades menores. A decisão sobre o que será a unidade é dependente da natureza do problema, dos objetivos da pesquisa e do tipo de materiais a serem analisados (MORAES, 1999, p. 12). 
Apesar de não ser uma situação ideal para analisar o fenômeno na metodologia da Análise de Conteúdo, ela nos permite analisar as unidades de contexto e não as unidades de registro e também nos permite usar categorias predeterminadas a partir do contexto investigado.

Nas atividades de mapas conceituais e produção de experimentos e textos, as categorias temáticas foram: reflexão sobre a atividade e reflexão para a docência. Para a atividade de edição e produção de vídeos, as categorias temáticas foram: reflexão sobre os vídeos produzidos; reflexão sobre a atividade e reflexão para a docência.

\section{Atividades propostas}

Na disciplina de Estágio Supervisionado em Física II, foram trabalhadas cinco atividades, assim distribuídas: mapas conceituais; a Física do cotidiano; experimentos e textos; jogos; simuladores e vídeos. A dinâmica das atividades seguiu sempre o mesmo princípio, ou seja, inicialmente uma abordagem teórico-metodológica sobre o assunto, seguida de um momento para discussão inicial do tema. Na sequência, a proposta da atividade para que os licenciandos desenvolvessem suas produções e posteriormente apresentassem em sala de aula. Para finalizar, um debate sobre as apresentações, os materiais produzidos e as possíveis formas de utilizá-los em sala de aula. Sempre que uma correção no material produzido fosse necessária, um novo prazo era indicado para a entrega do material corrigido.

A seguir, detalhes de como foram desenvolvidas cada uma das atividades propostas.

$\mathrm{Na}$ atividade com Mapas Conceituais, abordou-se a metodologia da Aprendizagem significativa e da técnica de elaboração de mapas conceituais. A partir disso, os licenciandos foram instruídos a elaborarem um mapa conceitual sobre o tema Energia. Após todos terminarem, passou-se para a construção de um mapa conceitual coletivo no quadro, onde todos os licenciandos contribuíram sugerindo alguma ligação ou conceito sobre o tema. $\mathrm{Na}$ parte final da atividade, discutiu-se o respectivo mapa conceitual coletivo analisando as ligações e os respectivos conceitos indicados.

Em relação à atividade da Física do Cotidiano, buscou-se desenvolver a habilidade escrita, a linguagem científica e sua transposição. Inicialmente foi abordada a relação da Física com o cotidiano das pessoas por meio de textos e de vídeos. Após a discussão sobre o tema, sobre os textos lidos e sobre os vídeos assistidos, os licenciandos foram instruídos a produzirem cinco ou mais textos curtos, abordando conceitos da Física no cotidiano das pessoas, utilizando uma linguagem leiga e didática a partir de uma pergunta. Por exemplo: "Por que as estrelas piscam?”; "Por que o céu é azul?”; "Por que o leite derrama ao ferver e a água não?”, entre outras.

A partir da pergunta norteadora, que se tornou o título, elaborou-se o texto que era a resposta à pergunta e, sempre que possível, deveria conter imagens para auxiliar a ilustrar os conceitos específicos daquele assunto. Após a apresentação de cada texto, realizou-se uma análise ressaltando os pontos positivos, as críticas e comentários em geral sobre os mesmos e instruções para correções. 
$\mathrm{Na}$ atividade de Produção de experimentos e de textos, iniciamos com uma exposição teórica e discussão sobre produção de experimentos, os benefícios e as dificuldades de se trabalhar com experimentação nas escolas. Na sequência, os licenciandos foram orientados a produzirem dois experimentos cada um e, para cada experimento, escreveram um texto de orientação e de apoio, a partir de um modelo. Após um tempo dedicado à construção dos experimentos e à produção dos textos, cada aluno apresentou suas produções em sala de aula, sendo ambos analisados e avaliados pelo docente e também pelos colegas.

Para a atividade de Edição e producão de vídeos, de início abordou-se alguns artigos e trabalhos na área de Física e/ou Astronomia que envolvem uso de materiais audiovisuais. Em seguida, assistiram a vários vídeos de diferentes abordagens e discutiram o seu potencial para utilização em sala de aula. Para orientar os licenciandos a editarem e produzirem seus próprios vídeos utilizouse o software gratuito Movie Maker (programa incluso no pacote de programas do Windows Live, que é gratuito). Um vídeo tutorial e um tutorial escrito foram elaborados para que os licenciandos aprendessem a utilizar o software. A atividade proposta foi a produção de um vídeo didático voltado para a Física ou Astronomia, que posteriormente foram apresentados e discutidos em sala de aula.

A atividade de Jogos no ensino de Física e Astronomia iniciou-se com uma abordagem da questão do lúdico e da produção e utilização de jogos. Para entender a dinâmica de um jogo educativo, foram disponibilizados alguns jogos de Física e de Astronomia para serem jogados. Após os jogos, discutiuse o potencial deles como recurso de ensino. A atividade proposta foi que os licenciandos, separados em grupos, elaborassem um jogo didático que envolvesse conteúdos de Física e/ou Astronomia. Esses jogos posteriormente foram jogados e analisados em sala de aula.

\section{RESULTADOS E DISCUSSÃO}

A pesquisa de doutorado no qual esse trabalho foi baseado apresenta a análise completa de todas as atividades propostas e foi organizada atribuindose a cada licenciando participante da pesquisa a denominação de uma letra de $A$ até $F$ e também a cada unidade de contexto identificada um correspondente numérico $(1,2,3, \ldots)$ na ordem em que elas são encontradas nos respectivos memoriais. Exemplo: D10 é a décima unidade de contexto extraída do memorial do licenciando D. As unidades marcadas com asterisco foram classificadas em mais de uma categoria.

A tabela abaixo (Tabela 1) é uma compilação com todas as unidades de contexto selecionadas para análise e tem o objetivo de apresentar um quadro geral de como as unidades de registro estão distribuídas entre as categorias dentro de cada atividade proposta. 


\begin{tabular}{|c|c|c|c|c|c|c|}
\hline \multicolumn{7}{|c|}{ Licenciandos } \\
\hline & $A$ & B & C & D & $E$ & $\mathrm{~F}$ \\
\hline \multicolumn{7}{|c|}{ Mapas Conceituais } \\
\hline $\begin{array}{c}\text { Reflexão sobre } \\
\text { a atividade }\end{array}$ & A3 e $A 4$ & B1 & $\begin{array}{l}\mathrm{C} 1, \mathrm{C} 2 \mathrm{e} \\
\mathrm{C} 3\end{array}$ & D1 & & F1 \\
\hline $\begin{array}{l}\text { Reflexão para a } \\
\text { docência }\end{array}$ & A1 e $A 2$ & & & D2 & E1 & \\
\hline \multicolumn{7}{|c|}{ A Física do cotidiano } \\
\hline $\begin{array}{c}\text { Reflexão sobre } \\
\text { a atividade }\end{array}$ & A5 & B2 & C4 e C6 & D3 e D4 & E2 & $\mathrm{F} 2$ \\
\hline $\begin{array}{l}\text { Reflexão para a } \\
\text { docência }\end{array}$ & & & C5 & & & \\
\hline \multicolumn{7}{|c|}{ Produção de experimentos e de textos } \\
\hline $\begin{array}{c}\text { Reflexão sobre } \\
\text { a atividade }\end{array}$ & A7 & B3 & $\mathrm{C7}$ & & E4* & $\mathrm{F} 3$ e $\mathrm{F} 4$ \\
\hline $\begin{array}{l}\text { Reflexão para a } \\
\text { docência }\end{array}$ & A6 & & $\mathrm{C} 8$ & D5 & E3 e E4* & \\
\hline \multicolumn{7}{|c|}{ Jogos no Ensino de Física e de Astronomia } \\
\hline $\begin{array}{c}\text { Reflexão } \\
\text { sobre os jogos } \\
\text { produzidos }\end{array}$ & $\begin{array}{l}\text { A8, A9 e } \\
\text { A10 }\end{array}$ & B6 e B7 & $\begin{array}{l}\text { C11, C12 } \\
\text { e C13 }\end{array}$ & D7 & E10 & F5 \\
\hline $\begin{array}{c}\text { Reflexão sobre } \\
\text { a atividade }\end{array}$ & $\begin{array}{l}\text { A11, A12 } \\
\text { e A14 }\end{array}$ & & C14 & D8* & E9* & F6 \\
\hline $\begin{array}{l}\text { Reflexão para a } \\
\text { docência }\end{array}$ & A13 & & & D8* & E9* & \\
\hline \multicolumn{7}{|c|}{ Edição e produção de vídeos } \\
\hline $\begin{array}{c}\text { Reflexão sobre } \\
\text { os vídeos } \\
\text { produzidos }\end{array}$ & A 15 e A16 & B5 & C9 & & & F7 \\
\hline $\begin{array}{c}\text { Reflexão sobre } \\
\text { a atividade }\end{array}$ & A18 e A19 & B4 & & D6* & $\begin{array}{c}\text { E5, E6 e } \\
\text { E7 }\end{array}$ & F8 \\
\hline $\begin{array}{l}\text { Reflexão para a } \\
\text { docência }\end{array}$ & A17 & & C10 & D6* & E8 & \\
\hline
\end{tabular}

Tabela 1: Unidades de registro e suas respectivas categorias. Autoria própria. 
Como este é um espaço limitado para apresentação do trabalho, apresentaremos as análises detalhadas de somente três das cinco atividades, são elas: Mapas Conceituais, Produção de experimentos e de textos e Uso de tecnologia no ensino de Física. Elas foram escolhidas por se destacarem mais em relação às outras atividades.

Elas também permitiram detectar e examinar as reflexões dos alunos sobre as atividades e as ações sugeridas por esta pesquisa, permitindo investigar o tema principal.

\section{Mapas conceituais - Categoria: Reflexão sobre a atividade}

\section{Nessa categoria, agrupamos as reflexões dos licenciandos sobre toda atividade proposta.}

A3: (sobre o mapa conceitual coletivo) (...) ao término, o professor finalizou a atividade explicando todas as ideias ali contidas e ficou muito legal a união das ideias e como elas estavam concatenadas.

A4: Um detalhe percebido pelo professor foi o fato de alguns de nós terem focado na parte conceitual de energia, dizendo quais eram as equações, unidades, etc. e outra parte focado nas relações existentes entre energia e cotidiano, com suas transformações, etc. Para uma sala de aula, a parte que relaciona o cotidiano dos alunos seria mais bem aproveitada, pois a parte conceitual mesmo não será muito interiorizada.

B1: Para mim essa atividade foi um pouco chata, pois, eu não conseguia reunir palavras que relacionassem com a ideia central, por mais simples que fosse, acho que esse tipo de atividade quando realizada requer um domínio na elaboração do que se pretende mapear, sendo uma avaliação da aula que você pretende abordar, como também se requer um objetivo ao qual se pretende verificar.

C1: Quando todos já haviam completado e dado a sua explicação, começamos a analisar, vimos que nos prendemos muito nos conceitos físicos de energia (exemplo, energia mecânica, energia relativística, etc.) e não nos preocupamos sobre as formas de energia que estavam relacionadas ao nosso dia a dia (energia eólica, energia química, etc.) e que nós utilizamos. E se tivéssemos que mostrar para um aluno ele ia compreender mais se tivéssemos relacionado ao cotidiano dele.

C2: No início não gostei da atividade, porque deu muito trabalho e para fazermos um mapa conceitual, pois para fazer temos, no meu conceito, que "dominar", saber do tema e na hora esquecemos tudo sobre aquele assunto. No final, quando juntamos a ideia da turma, vimos que saiu um mapa conceitual muito bom, porque cada um se prendeu a uma parte, uns ficaram mais relacionados a conceitos e outros relacionaram ao cotidiano.

C3: Mas no final gostei da atividade, conseguimos ver a importância do mapa conceitual e percebemos que ela pode ser usada no ensino, em provas, para se conhecer as preconcepções dos alunos e foi bom, aprendemos bastante.

D1: Eu particularmente sinto um pouco de dificuldade em elaborar um mapa conceitual, porque não é algo fácil. 
F1: Particularmente, gostei da atividade, nunca havia visto um mapa conceitual e nunca havia criado um. A junção dos mapas individuais se mostrou bem interessante, percebi como é diferente a visão que cada um tem sobre um determinado tema e como diferentes visões completam o tema. A atividade de elaboração do mapa demonstrou-se bem interessante.

Nas unidades de registro dessa categoria, houve uma divisão clara de destaques na atividade. Os licenciandos B, C e D focaram suas reflexões na dificuldade inicial de construir o mapa conceitual sobre o tema proposto. Nesse tipo de situação, eles deveriam pensar de uma forma diferente do que normalmente pensam ou da forma como foram ensinados a pensar. Indicar conceitos ligados ao tema central é fácil, difícil é indicar o modo como eles se relacionam, em especial na primeira vez que estão fazendo isso. De início eles acreditaram que precisariam ter um domínio sobre o assunto, quando na verdade, o objetivo era, como expresso por Moreira (2007, p. 5), "avaliar a organização conceitual que o aprendiz atribui a um determinado significado", ver quais as relações que cada um faz com o tema central proposto e que ele já possui independentemente de ter domínio ou não do assunto.

Já os licenciandos A e F focaram suas reflexões no mapa conceitual coletivo, elaborado a partir da contribuição de todos com conceitos e relações. Eles perceberam que todos conseguem contribuir com ideias para essa construção coletiva, o que a princípio eles não esperavam por isso. Achavam que os últimos não teriam mais o que incluir, mas ficaram surpresos pela forma como todos conseguiram apresentar conceitos e relações e também como cada um consegue pensar de forma muito diferente do outro sobre o mesmo tema.

Moreira (2007) sugere que não existe um mapa conceitual correto ou errado, pois ele representa como se relacionam os conceitos, e isso é diferente para cada pessoa pela vivência que cada uma delas tem. Todos os licenciandos, não somente A e F, expressaram sua compreensão sobre isso.

Quando fizemos a análise do mapa conceitual coletivo, foi clara uma divisão das ideias expostas em duas linhas de conceitos: uma voltada para as definições físicas de energia; e a outra para a relação entre energia e o cotidiano das pessoas, como tipos e aplicações de energia. Como todos os licenciandos estão no curso de graduação em Física e, até aquele momento, quase todas as disciplinas do curso eram exclusivamente de Física (experimental, teórica, conceitual ou cálculos), ficou evidente no mapa conceitual coletivo que um grupo conseguiu dispersar um pouco os conceitos apresentados das definições puras e partiram para algumas relações com o cotidiano. O licenciando A, ao refletir sobre isso, reconhece que em uma sala de aula trabalhando com alunos, seria mais proveitoso privilegiar as relações do tema central com o cotidiano das pessoas, para melhor compreensão.

\section{Mapas conceituais - Categoria: Reflexão para a docência}

Nessa categoria, agrupamos as reflexões dos licenciandos sobre a importância da atividade para a sua formação ou a importância para o professor, a partir da experiência adquirida na atividade. 
A1: Assim, fica uma alerta para nós, futuros docentes, pois não basta apenas despejar os conteúdos sobre os alunos, sem se preocupar com quais são suas concepções alternativas (...).

A2: Fazem-se necessário, novas formas de ensino para tornar a aprendizagem significativa, para tornar-se possível atingir não apenas um pequeno grupo de alunos, mas boa parte da sala.

D2: Posso usar mapas conceituais também para mostrar para os alunos como os conteúdos e conceitos físicos estão interligados entre eles, que para min realmente acredito ser muito proveitoso em sala de aula (...).

E1: Mapas conceituais são alternativas de ensino, que se mostram bastante úteis para o professor utilizar em sala de aula, podendo ser usado como uma referência simples, porém essencial.

O licenciando A é o que conseguiu assumir o nível mais intenso de reflexão para essa categoria. A partir de toda a análise e dos debates sobre a atividade, ele reconhece a importância dos conceitos que os aprendizes já possuem interiorizados têm para o professor poder trabalhar os novos conceitos e também com várias metodologias de ensino diferentes. Segundo Moreira (2007, p. 5), "mapas conceituais podem levar a profundas modificações na maneira de ensinar, de avaliar e de aprender". Por esse motivo, foi importante o reconhecimento de que cada um aprende de uma forma diferente. A mesma opinião tem o licenciando $\mathrm{E}$, assim como todos os outros na reflexão em sala de aula.

O licenciando D dá uma atenção especial à importância que as ligações entre conceitos têm, ao construir um mapa conceitual, já refletindo para um eventual momento, quando ele estiver atuando como professor, utilizando essa metodologia em sala de aula. Para Moreira (2007),

À medida que os alunos utilizarem mapas conceituais para integrar, reconciliar e diferenciar conceitos, à medida que usarem essa técnica para analisar artigos, textos, capítulos de livros, romances, experimentos de laboratório, e outros materiais educativos do currículo, eles estarão usando o mapeamento conceitual como um recurso de aprendizagem (p. 5).

Ele compreendeu que essa relação entre conceitos não éimportante somente para a construção de mapas conceituais, mas que contribui também para que os professores possam promover uma verdadeira aprendizagem significativa para seus alunos.

\section{Produção de experimentos e de textos - Categoria: Reflexão sobre a atividade}

Nessa categoria, agrupamos as reflexões dos licenciandos sobre a atividade proposta.

A7: Essa atividade foi muito proveitosa, frente aos desafios encontrados para preparar um material didático diferenciado, que possa ser aproveitado em sala de aula, visto a dificuldade em preparar esses experimentos. A montagem dos experimentos foi muito interessante e, até mesmo divertida, estimulando nossa criatividade. A parte mais trabalhosa e chata foi além de fazer o experimento funcionar, fazer o texto, que exigia todos os detalhes da montagem. 
B3: Eu achei a atividade da elaboração dos experimentos muito legal, a única parte que deu mais trabalho foi conseguir tirar foto, pois meus pais não conseguiam tirar com meu celular, onde tive que pedir ajuda a um amigo. Logo na montagem até aprendi a usar a furadeira.

C7: Bem, achei a atividade muito legal, principalmente a parte da montagem, o chato foi à parte de organizar as fotos e fazer o passo a passo, pois tínhamos que colocar muitos detalhes para que se outra pessoa pegar o nosso texto conseguisse reproduzir. Porém trabalhamos a parte escrita e com isso aprendemos e melhoramos nossa maneira de escrever.

E4*: Considero essa atividade importante, pois nos mostrou que somos capazes de desenvolver vários experimentos de física a serem usados em sala de aula, penso ainda em montar meus próprios experimentos e levá-los futuramente em sala de aula.

F3: Apesar de ter perdido praticamente toda a atividade ela se mostrou bem interessante, a realização dos experimentos se demonstrou um tanto trabalhosa, mas mais trabalhosa ainda foi a criação da apostila que demonstrava como executar o experimento passo a passo, também deveríamos escrever como abordar o tema em questão no ensino da física.

F4: Vemos nessa atividade o quão difícil é ser claro para a demonstração e o quão difícil é aplicar o tema para o ensino, já que cada pessoa tem sua própria forma de ensinar.

Como parte do desafio proposto na atividade, os licenciandos escreveram textos de apoio para cada experimento, sendo o principal item uma explicação bem detalhada sobre como montar o experimento, incluindo várias fotografias para ajudar a detalhar os procedimentos. Apesar de já terem trabalhado com experimentos de física anteriormente, foi difícil para eles explicarem a montagem para outra pessoa que eventualmente viesse a ler o texto. Alguns até consideraram chata essa etapa porque normalmente eles não trabalham de forma metódica, mas todos foram unânimes em reconhecer a importância desse trabalho detalhado.

É diferente para o licenciando fazer um experimento para si do que fazer um experimento pensando em como explicar, elaborando um texto de como montar e de como utilizá-lo. Para a elaboração desse texto, é importante prever as dificuldades que outras pessoas possam ter ao tentar recriar o experimento proposto. Isso nem sempre é fácil, por isso a escolha das fotografias ensinando os passos mais difíceis é importante e os alunos compreenderam isso. Fazer algo para si é muito mais fácil do que fazer algo explicando para outras pessoas.

Pudemos perceber que a realização dessa atividade foi realmente importante para os licenciandos, que notaram uma melhora na sua escrita, na sua argumentação e na sua linguagem.

Essa montagem do experimento também tem outro lado positivo, ao elaborar os experimentos para fotografar os passos da montagem, os licenciandos tiveram que se dedicar para fazer essa montagem bem-feita e organizada, assim como também manusear diversas ferramentas, como furadeira e serra. Durante as reflexões ficou clara a satisfação em ver terminado algo que eles montaram e também por compreenderem que são capazes de produzir recursos para utilizar em suas aulas no futuro. Esse é um dos principais pontos positivos dessa atividade. 


\title{
Produção de experimentos e de textos - Categoria: Reflexão para a docência
}

Nessa categoria, agrupamos as reflexões dos licenciandos sobre a importância da atividade. Aqui, as unidades de contexto convergem para a transposição do conhecimento adquirido como licenciando para pensá-lo como professor.

\begin{abstract}
A6: O objetivo desse trabalho era além de montar um texto (treinando nossa escrita), elaborar um projeto para nos dar uma nova alternativa de ensino, para que futuramente, quando formos dar aula, não levarmos um experimento em sala de aula sem estarmos preparados.

C8: A produção do texto e os experimentos, não somente só o meu mais o da turma, dão muito suporte para quando formos levar em sala de aula, com eles tivemos que analisar as possibilidades no ensino de Física e de que maneira poderia ser trabalhado e aplicado. Além do fato, que se levados em sala de aula, os experimentos vão chamar a atenção dos alunos e despertar o interesse, pois são aulas muitas vezes diferenciadas, pois a maioria dos professores não utiliza esse recurso.
\end{abstract}

D5: Eu gostei muito desta atividade, achei muito interessante e significativa para minha profissionalização, essa instrumentação para licenciatura é de extrema importância para essa transformação que o ensino de física está passando, com esses experimentos podemos mostrar para os alunos de forma que assemelhem melhor a aplicação de conceitos físicos e sua importância para a vida como forma de compreender melhor o mundo em que vivemos e acho que todos os professores deviam se preocupar e se esforçar para fazer algo bacana e enriquecer suas aulas, e assim motivar melhor os alunos, para o ensino de ciências.

E3: Experimentos de física são excelentes recursos para o ensino, qualquer professor é capaz de montar os seus e utilizá-los em sala de aula. Os custos geralmente não são elevados e a montagem pode ser simples ou um pouco mais complicada, de qualquer forma o esforço de montá-los será recompensado, pois os alunos gostam quando o professor foge um pouco da teoria apresentando-lhes algo prático.

E4*: Considero essa atividade importante, pois nos mostrou que somos capazes de desenvolver vários experimentos de física a serem usados em sala de aula, penso ainda em montar meus próprios experimentos e levá-los futuramente em sala de aula.

Ao pensar como professor, o licenciando muda sua prioridade, que passa a ser a aprendizagem de seus alunos. Essa transposição é um passo muito importante em sua formação. Ao pensarem na aprendizagem dos alunos, começam a desenvolver uma capacidade reflexiva benéfica ao analisarem a eficiência que os recursos utilizados pelos professores podem ter e também no modo como atrair o interesse deles por esses recursos e pelas aulas de Física. Isso é muito importante para um professor. Para Araújo e Abib (2003),

A análise do papel das atividades experimentais desenvolvida amplamente nas últimas décadas revela que há uma variedade significativa de possibilidades e tendências de uso dessa estratégia de ensino de Física, de modo que essas atividades podem ser concebidas desde 
situações que focalizam a mera verificacão de leis e teorias, até situações que privilegiam as condições para os alunos refletirem e reverem suas ideias a respeito dos fenômenos e conceitos abordados, podendo assim atingir um nível de aprendizado que lhes permita efetuar uma reestruturação de seus modelos explicativos dos fenômenos (p. 177).

Ou seja, não basta aprender a montar e apresentar os experimentos de Física, é preciso que o professor estruture a forma de trabalho com esse recurso. A atividade proporciona o contato inicial, espera-se que, a partir disso, os licenciandos se conscientizem dessa importância e sempre reflitam e estudem a melhor forma de abordar os experimentos em sala de aula, de acordo com o objetivo proposto.

Reconhecidamente, a falta de interesse dos alunos pelas aulas de Física é um dos principais problemas enfrentados pelos professores. Assumir essa dificuldade e trabalhar para superá-la não só é benéfico para os alunos, mas também o é para a relação professor-aluno, porque eles vão notar o empenho do professor em querer fazer algo diferente e, quem sabe, interessar-se mais pelos assuntos abordados. No caso dos experimentos de Física, há uma quantidade substancial de material à disposição dos professores, conforme indica Laburu (2005):

Hoje em dia é substancial o "showroom" de experimentos e equipamentos didáticos com os quais se pode tomar contato pelos periódicos, livros, "sites" e eventos da área de ensino de ciências, como, também, por ocasião de cursos de extensão, pela televisão ou por catálogos comerciais e, ainda, mais raramente, em locais de exposições permanentes, possíveis de serem visitados em alguns grandes centros. Isto sem contar com o presumível contato obrigatório que deveriam ter os futuros profissionais de cada área, durante os seus cursos específicos de licenciatura (p. 162).

O trabalho com experimentos, por si só, já é muito importante para os licenciandos aprenderem a trabalhar com esse recurso, mas um ponto que se destacou nessa atividade é que eles realmente assumiram a postura de elaborar as atividades pensando na eficiência e na aplicação do recurso de ensino em sala de aula, com o objetivo de melhorar a aprendizagem e despertar o interesse dos alunos. Para Quirino e Lavarda (2001),

O uso de experimentos pode ser uma possibilidade de transição dos modelos tradicionais de ensino para a construção de formas alternativas de ensinar Física. De acordo com nossa experiência, quando o professor introduz os experimentos em uma sala de aula comum, ele se vê frente a um novo comportamento dos alunos mais interessados e participativos (p. 118).

Muitas vezes, não há a necessidade de usar recursos complicados e caros. Os experimentos de Física são exemplos disso, muitos deles são bons e podem ser facilmente montados com materiais de baixo custo. Isso é uma vantagem porque, segundo Quirino e Lavarda (2001, p.118), “(...) a realidade de excesso de trabalho e as precárias condições do ensino no Brasil são fatores que, somados, desestimulam o professor a se utilizar deste procedimento". O importante é que os professores se conscientizem de que coisas simples, de fácil montagem e baratas podem realmente fazer a diferença em sala de aula. 


\section{Edição e produção de vídeos - Categoria: Reflexão sobre os vídeos produzidos}

Nessa categoria, agrupamos as opiniões dos licenciandos que remetem exclusivamente aos vídeos produzidos por eles.

A15: (sobre o vídeo produzido pelo grupo dela) Uns dos pontos negativos, que já havia sido visto por nós, porém não conseguimos editar esse detalhe, foi o fato de alguns slides terem muito texto e o vídeo passar muito rápido, não dando tempo de lê-lo.

A16: Montar os slides foi o que menos nos preocupou e deu trabalho. O grande desafio é tornar tudo aquilo um vídeo. Por fim, o resultado foi muito legal, porém não tenho facilidade para mexer com programas de computador e não é algo que me agrada muito também.

B5: Como foi o primeiro vídeo que fizemos teve alguns erros, como a fonte ter ficado pequena e a velocidade de cada slide ter ficado um pouco rápida, mas comparado a alguns vídeos que o professor mostrou, o nosso ficou muito bom, um pouco mais de prática $\mathrm{e}$ esses erros podem ser corrigidos.

C9: Mas em geral, gostei de fazer, pois aprendemos a confeccionar o vídeo, como colocar figuras, textos, como cortar e utilizar a música com coerência ao vídeo.

F7: Nesta atividade, encontramos algumas dificuldades na hora de edição de vídeo, visto que esquecemos que o professor havia passado os vídeos tutoriais sobre edição. Em nosso grupo, E ficou encarregado de editar o vídeo, mas teve problemas e por isso, tive que editar o vídeo eu mesmo.

Antes de iniciar a elaboração do vídeo, os licenciandos deveriam planejar em grupo qual o objetivo que eles queriam alcançar e também definir a estrutura do vídeo. Como foram mostrados a eles diferentes tipos e quais poderiam utilizar, eles precisaram usar a criatividade para fazer esse planejamento. Para todos eles, apesar de terem acesso e assistirem a inúmeros vídeos em seu dia a dia, essa foi a primeira vez que precisaram elaborar um vídeo e por isso, essa atividade também representou um desafio para os mesmos.

A estrutura do vídeo é muito importante para a obtenção ou não do sucesso pretendido, por isso se faz necessário um planejamento cuidadoso. Um simples item como música de fundo, imagens utilizadas, slides com muito texto, letras pequenas ou texto passando rápido demais, pode dificultar a compreensão do assunto abordado. Pela inexperiência, o que já era esperado, muitas das dificuldades enfrentadas pelos grupos foram em relação a esses aspectos. A partir do que foi aprendido, eles têm condições de continuarem a aperfeiçoar os vídeos, transformando-os em um recurso realmente útil para o ensino de Física.

Essa atividade foi proposta em grupo por causa dos benefícios que esse tipo de trabalho pode fornecer. Conforme Silva e Villani (2012), essas atividades

(...) favorecem a comunicação entre os alunos e entre estes e o professor; permitem que o professor perceba as interações que ocorrem entre os alunos em grupo auxiliando-os nas 
suas intervenções; desenvolvem a habilidade de ouvir e se fazer ouvir durante as discussões, gerando um clima de cooperação e colaboração (p. 184).

Como a elaboração do vídeo é complexa, a cooperação entre o grupo é fundamental e um dos grupos não conseguiu coordenar os trabalhos, por causa disso, tiveram dificuldades para realizar a atividade, gerando estresse entre os membros, mesmo assim, eles conseguiram fazer um bom vídeo. Essa atividade em grupo mostrou aos licenciandos a importância de aprenderem a trabalhar melhor em equipe e foram orientados sobre essa questão.

Silveira, Leão e Lins (2008) também apontam vários benefícios da produção de vídeos na formação do professor:

1. A vantagem mais rudimentar da produção de vídeo é o saber como se constrói; como funciona; como provoca nossas emoções;

2. O caráter motivador: a motivação parte da iniciativa de produzir um recurso didático que será socializado. O vídeo como produto final será exibido para os alunos, que dependendo do objetivo e qualidade didática do vídeo, podem ter a aprendizagem beneficiada.

3. Para construir o vídeo didático o professor precisa pesquisar mais.

4. Facilitam a contextualização. As ações de pesquisa e adequação do texto escrito à linguagem audiovisual proporcionam uma maior facilidade na transposição didática do conceito científico para o vídeo. Além disto, os professores ampliam seus conhecimentos na construção do roteiro e melhoram as destrezas para o manejo de diferentes instrumentos técnicos.

5. O trabalho colaborativo garante um aprendizado maior com o outro. A divisão de tarefas, o saber ouvir, o saber falar e o saber executar implica um maior amadurecimento dos participantes para a concretização de um recurso que vai expor a(s) ideia(s) de todos (p. 7-8).

Valendo-nos desses benefícios sobre o uso de vídeos na formação do professor como parâmetro, podemos ver que, nessa atividade conseguimos trabalhar com todos esses itens, apesar de um dos grupos ter tido problemas de cooperação entre os membros.

\section{Edição e produção de vídeos - Categoria: Reflexão sobre a atividade}

Nessa categoria, agrupamos as reflexões dos licenciandos sobre a atividade proposta.

A18: Para mim, foi um diferencial para trabalhar com isso, pois, apesar de já ter utilizado vídeos e, muitas vezes já precisei editá-los, nunca me propus a fazê-lo, pois acreditava ser algo muito difícil e minha apatia com relação a isso não me motivava a aprender.

A19: Essa atividade fez com que eu modificasse minhas concepções e o resultado me agradou bastante. 
B4: Eu particularmente adorei essa atividade, mesmo com as dificuldades, por nunca ter mexido no programa, acabei aprendendo a produzir vídeos e a cortar músicas, que vão me ajudar muito na produção de vídeos para trabalhar com meus alunos no Ensino Médio.

D6*: (...) achei legal fazer o vídeo, também acho muito interessante fazer vídeos para atividades extraclasses, assim como no Colégio Sapiens, onde eu já fiz cursinho, tinham vídeos com as matérias, para os alunos assistirem, matérias perdidas, ou revisar mesmo.

E5: Vídeos educativos são úteis em sala de aula, principalmente porque ajuda o aluno a fixar determinados conceitos. Existem inúmeros vídeos disponíveis na internet voltados ao ensino de física, com um conhecimento mínimo de informática podemos usá-los para melhorar nossas aulas.

E6: Particularmente gostei de desenvolver essa atividade, pois pouco sabia sobre edição de vídeos, foi uma oportunidade de aprender mais sobre o assunto.

E7: Essa atividade nos deu menos trabalho para ser feita do que os jogos educativos, que também fizemos em grupo (...).

F8: Apesar das dificuldades, geradas por nós mesmos, a atividade se demonstrou bastante empolgante, particularmente nunca havia editado um vídeo e o fato de ver o vídeo pronto foi bastante satisfatório, gostei bastante dessa atividade, pois tive o prazer de aprender algo que eu nunca tinha feito.

Quase todos os licenciandos estavam participando ou já participaram de algum projeto (Programa de Educação Tutorial, Programa Institucional de Bolsa de Iniciação à Docência, Extensão, Museu Dinâmico Interdisciplinar) e em algum momento tiveram a oportunidade de usar um vídeo qualquer do Youtube ou um trecho de filme. Apesar disso, não sabiam fazer uma edição para extrair e utilizar só a parte que lhes interessava. Apesar da dificuldade que a primeira vez sempre traz, os alunos reconheceram que não é difícil utilizar o software para a edição de vídeos. O software trabalhado com os alunos é gratuito e o mais simples possível. Por mais que existam softwares completos, de qualidade e com alto custo, a estrutura básica e a forma de elaborar os vídeos é a mesma não importando o software. A diferença está na quantidade de recursos disponíveis. Esse ponto foi importante porque os licenciandos pensavam que fazer edição de vídeos era muito difícil e que precisava de softwares muito caros.

Ao aprenderem a editar e a produzirem vídeos, eles adquiriram a capacidade de trabalhar e de desenvolver mais um recurso de ensino que pode complementar todos os outros já trabalhados na disciplina. Após a atividade, ficou claro que eles não conheciam o verdadeiro potencial do uso de vídeos. Adquirir a habilidade de produzir seus próprios vídeos é uma grande vantagem, assim como é fácil à socialização do recurso para os alunos, para outros professores e, na internet, para qualquer um acessar.

A partir dessa atividade, os alunos reconheceram a importância que o uso da tecnologia tem para a formação do professor e o quanto ela pode ajudar no processo de ensino-aprendizagem, uma vez que a tecnologia está cada vez mais inserida no ambiente escolar e principalmente na vida das pessoas. Para Menezes et al (2009), 
As Tecnologias de Informação e Comunicação (TICs) são essenciais no processo ensinoaprendizagem, tanto presenciais quanto a distância ou semipresenciais, pois a sociedade em geral já foi invadida por vários equipamentos eletrônicos, como celulares de $3^{\mathrm{a}}$ geração (3G), TV digital interativa, i-podes, PS3, etc. O surgimento de novas tecnologias incrementa o mercado, prometendo facilitar nossa vida e, isso, certamente, precisa de um novo questionamento sobre o uso das mesmas nas escolas. A incorporação das TICs no contexto escolar deve proporcionar aos estudantes novas situações de aprendizagem bem como aos professores (p. 6).

É importante para o professor saber utilizar essa tecnologia, não somente para interagir melhor com os alunos, mas também para explorá-la com um objetivo educacional. Hoje, temos à disposição computadores, internet, tablets, smartphones e precisamos aproveitar esses recursos. Smartphones e tablets têm vários sensores embutidos e possuem vários aplicativos que utilizam esses sensores e que poderiam ser usados em sala de aula, tais como cronômetro, decibelímetro, a câmera fotográfica, nível, planetário, GPS e muitos outros. Como reconhecimento dessa importância, o Governo Federal, por meio de um projeto do Ministério da Educação, iniciou, desde o ano de 2012, distribuição de tablets para professores da rede pública de ensino. Além disso, vários estados têm programas para a inserção de tecnologia na sala de aula, com computadores, projetores multimídia ou com lousas digitais.

\section{Edição e produção de vídeos - Categoria: Reflexão para a docência}

Nessa categoria, agrupamos as reflexões dos licenciandos sobre a importância da atividade para a sua formação a partir da experiência vivida com a atividade.

A17: Essa atividade foi de grande valia, pois é fundamental que um professor tenha um mínimo de conhecimentos sobre como usar as tecnologias a seu favor e saber editar um vídeo, ou até mesmo montar um com o objetivo que se quer trabalhar é fundamental atualmente.

C10: E no final podemos aprender e ter um conhecimento maior em como utilizar o vídeo, essa tecnologia em nosso favor em sala de aula, que muitas vezes gera grande interesse e atenção por parte dos alunos.

D6*: (...) achei legal fazer o vídeo, também acho muito interessante fazer vídeos para atividades extraclasses, assim como no Colégio Sapiens, onde eu já fiz cursinho, tinham vídeos com as matérias, para os alunos assistirem, matérias perdidas, ou revisar mesmo.

E8: (...) analisando os resultados obtidos considero mais relevante a atividade dos jogos, pois acho que é uma alternativa de ensino melhor.

Os licenciandos passaram a enxergar os vídeos com "outros olhos", refletindo sobre situações anteriores com o uso de vídeos e também sobre possibilidades de utilização do recurso, em sala de aula ou fora dela. Para eles, foi uma experiência nova e importante em sua formação. 
Apesar de terem bastante contato com a tecnologia, essa atividade mostrou que eles precisam compreender e saber usar a tecnologia com o objetivo de promover um melhor ensino de Física, e que a tecnologia pode ser inserida no ambiente de sala de aula de forma muito mais ampla que atualmente. Para Silveira, Leão e Lins (2008),

\footnotetext{
Na produção de vídeos, o poder de criação e imaginação dos alunos foram postos à prova. Criar e imaginar foram requisitos primordiais para o desenvolvimento da atividade, sem ser aspectos puramente motivacionais. Eles foram tão importantes na concretização do vídeo quanto os próprios conteúdos científicos que envolviam o tema (p.14).
}

O potencial do uso de vídeos no ensino de Física é grande não somente pela quantidade de temas que podem ser trabalhados, mas também pelos vários tipos e estruturas diferentes que podem ser utilizados. Por exemplo, pode-se elaborar um vídeo que sirva de introdução a um conteúdo novo a ser abordado, para complementar o conteúdo abordado em sala de aula ou para relacionar os conceitos físicos a situações do cotidiano ajudando na aprendizagem dos conceitos.

$\mathrm{O}$ vídeo pode ser usado para complementar qualquer outro recurso de ensino que um professor pode utilizar, também sendo muito fácil a sua socialização. Isso é importante porque, segundo Menezes et al (2009),

\footnotetext{
Muitas vezes, encontramos, dentre nossos estudantes, em sala de aula, aqueles que não se contentam apenas em ouvir o professor, eles precisam copiar (visão) a fala do mestre. Do mesmo modo, há aqueles que não conseguem entender o conteúdo apenas lendo, precisam escutar o conteúdo (p. 6).
}

O professor precisa utilizar recursos e metodologias de ensino diferentes para tentar alcançar o máximo de alunos, pelas diferenças como cada aluno aprende.

Menezes et al (2009, p. 6) apresentam os resultados da pesquisa de Canabrava e Vieira (2006), na qual elas concluíram que "o emprego adequado desses recursos didáticos, quando combinado a mais de dois estímulos, eleva a retenção das mensagens (dados e informações) em 35\% e as conservam na memória por período maior". Isso mostra o quão poderoso pode ser o recurso audiovisual, quando usado adequadamente aliado a outros materiais didáticos.

Em uma época em que a sociedade e a cultura estão se tornando cada vez mais audiovisuais, a capacidade de editar e de produzir vídeos será cada vez mais necessária, assim como a capacidade de usar outros recursos tecnológicos como, internet, sites, blogs, fóruns, simuladores, softwares e aplicativos de smartphones.

\section{CONSIDERAC̣ÕES FINAIS}

Acreditamos ser necessária uma reformulação nos cursos de formação inicial de professores de Física e este trabalho apresentou uma forma diferenciada que propicia a transformação do aluno para um participante interativo, crítico e reflexivo por meio de uma formação pluralista-reflexiva. Para conseguir isso, 
demos oportunidade para que os licenciandos tivessem o máximo de contato com vários recursos e metodologias de ensino, produzindo e analisando coletivamente essas produções dentro do escopo da disciplina.

Sobre a atividade de Mapas Conceituais, apesar das desconfianças e das dificuldades iniciais relativas à elaboração do mapa conceitual, que nenhum licenciando tinha feito antes, todos gostaram da atividade. Ao terem contato com essa metodologia de ensino, eles passaram a enxergá-la como um recurso que realmente pode ser utilizado na sala de aula e de diversas formas. Foi marcante a construção do mapa conceitual coletivo, não só pelo resultado final, de um mapa conceitual muito mais completo, mas pelo fato de notarem que cada pessoa pensa de forma diferente e que a vivência de cada um influencia o modo de relacionar os conceitos.

Foi positivo quando os licenciandos perceberam que, a partir daquele momento, precisavam começar a pensar e agir não só como graduandos, mas também como futuros professores, e isso eles fizeram por meio da reflexão.

De todas as atividades propostas, a atividade da Produção de Experimento $e$ Textos foi a que criou um choque de realidade nos licenciandos. Experimentação é a metodologia de ensino mais citada, mais comentada e uma das mais utilizadas pelos professores da área e, muitas vezes, seu potencial é supervalorizado. Os licenciandos passaram a reconhecer os benefícios e dificuldades no uso da experimentação. Não basta simplesmente fazer e levar um experimento para a sala de aula, é preciso ter um planejamento do que fazer, do como fazer e com qual objetivo.

Propomos a produção do texto junto com o experimento para dar subsídios aos licenciandos para compreenderem que ao trabalhar com experimentação é preciso criar um ambiente em que se possa explorar o potencial dos experimentos como recurso. Essa atividade ofereceu aos licenciandos a oportunidade de compreenderem o potencial desse tipo de recurso.

Consideramos os resultados obtidos nessa atividade como positivos e um dos pontos que destacamos foi o fato dos alunos perceberem a capacidade e a motivação para produzirem seus próprios recursos para serem utilizados nas aulas de Física, aumentando a inter-relação entre os pares. Isso foi benéfico para o desenvolvimento deles como professores reflexivos e interativos.

$\mathrm{Na}$ atividade de Edição e produção de vídeos, os licenciandos perceberam que a produção de vídeos oferece variadas possibilidades para a criação de material didático sobre os conceitos físicos ou as relações da Física com o cotidiano das pessoas, com o objetivo de facilitar a aprendizagem na sala de aula. Também compreenderam que os professores podem e devem construir, gradativamente, um grande repertório de material audiovisual.

Nossos resultados combinam com resultados obtidos nas pesquisas envolvendo a importância de atividades diferenciadas para uma melhor formação do professor de Física, tais como: o uso de experimentação (RODRIGUES; MATTOS; LEOPOLDO, 2013), uso e produção de textos de divulgação científica (CORREIA, 2016), atividades com enfoque CTS (ROZA, 2011), mapas conceituais (BARRETO; RIBEIRO, 2012), formação reflexiva e a contextualização no ensino de Física (POLACZINSKI, 2011). Também destacamos pesquisas que investigaram a disciplina de Estágio Supervisionado em Física como desafio na formação docente (CONCEIÇÃO; SILVA, 2016; SCHWANTES, et al, 2011). 
Consideramos positivos os resultados obtidos com as atividades propostas e com isso, o próximo passo é continuar aperfeiçoando as atividades e desenvolvendo novas com o mesmo objetivo, melhorar a formação inicial do professor de Física propiciando condições para que os professores em início de carreira, consigam trabalhar com variados tipos de recursos em sala de aula, sempre visando uma melhor aprendizagem dos alunos.

\section{REFERÊNCIAS}

ABIB, M. L. dos S. Em busca de uma nova formação de professores. Ciência e Educação, Bauru, v. 3, p. 6072, 1996. In: CAMARGO, S.; NARDI, R. O discurso oficial, o discurso dos formadores e a demanda de licenciandos e professores em exercício na reestruturação de um projeto políticopedagógico para formação de professores de Física. X Encontro de Pesquisa em Ensino de Física, Londrina, Paraná, v. 1, 2006.

ABIB, M. L. dos S. A contribuição da prática de ensino na formação inicial de professores de Física. In: ROSA, D. E. G.; SOUZA, V. C. de. (org.). Didática e práticas de ensino: interfaces com diferentes saberes e lugares formativos. Editora DP\&A, Rio de Janeiro, 2002.

ARAÚJO, M. S. T. de; ABIB, M. L. V. dos S. Atividades experimentais no ensino de Física: Diferentes enfoques, diferentes finalidades. Revista Brasileira de Ensino de Física, v. 25, n. 2, 2003.

ARAÚJO, R. S. O conhecimento pedagógico do conteúdo na disciplina de metodologia para o ensino de Física: relato de experiência. XVIII Simpósio Nacional de ensino de Física. Vitória, Espírito Santo, 2009.

BARCELLOS, M.; KAWAMURA, M. R. D. Licenciatura em Física: As novas tendências e a pesquisa em ensino. VII Encontro Nacional de Pesquisa em Educação em Ciências. Florianópolis, Santa Catarina, 2009.

BARDIN, L. Análise de conteúdo. São Paulo: Edições 70, 2011.

BARRETO, E. G.; RIBEIRO, T. R. O mapa conceitual no processo de ensino e aprendizagem em Física: um estudo acerca da sua utilização como instrumento pedagógico no estágio supervisionado. In: VI Colóquio Internacional Educação e Contemporaneidade. São Cristovão, Ceará, 2012.

BRASIL. Ministério da Educação. Parâmetros Curriculares Nacionais. Brasília: Ministério da Educação, 1997.

CAMARGO, S.; et al. A reestruturação do projeto pedagógico de um curso de licenciatura em Física de uma universidade pública: contribuições de licenciandos ao processo. Ensaio: Pesquisa em Educação em Ciências (On-line), v. 14, p. 217-235, 2012.

CAMARGO, S.; NARDI, R. A linguagem no ensino de Física: interpretação de discurso de licenciandos num estágio supervisionado de regência. In: NARDI, R.; ALMEIDA, M. J. P. M de. Analogias, leituras e modelos no ensino da Ciência: a sala de aula em estudo. São Paulo: Escrituras Editora, 2006.

CONCEICAO, R. S.; SILVA, E. S. Formação de professor: desafios do estágio supervisionado em Física. In: $9^{\circ}$ Encontro Internacional de Formação de Professores, 2016, Aracaju. Anais $9^{\circ}$ Encontro Internacional de Formação de Professores, v. 9, 2016.

CORREIA, D. Textos de divulgação científica: leitura, produção e divulgação de atividades didáticas no espaço do estágio supervisionado em Física. Tese (Doutorado em Educação em Ciências) - Universidade Federal de Santa Maria. Santa Maria, 2016.

LABURÚ, C. E. Seleção de experimentos de Física no Ensino Médio: uma investigação a partir da fala de professores. Investigações em Ensino de Ciências, v. 10, n. 2, p. 161-178, 2005. 
LABURÚ, C. E; ARRUDA S. de M e NARDI, R. Pluralismo Metodológico no Ensino de Ciências. Ciência \& Educação, v.9, n. 2, p. 247-260, 2003.

LEODORO, M. P.; TEDESCHI, W. Rupturas na concepção tradicional sobre formação de professores: em busca de novas diretrizes. XVIII Simpósio Nacional de Ensino de Física, Vitória, Espírito Santo, 2009.

LIBÂNEO, J. C. Adeus professor, adeus professora. 13ª ed. São Paulo: Cortez, 2011.

MCLAREN, P. Utopias Provisórias. Petrópolis: Vozes, 1999.

MENEZES, A. P. S. et al. A história da Física contada em vídeos de curta duração: TIC como organizador prévio no Ensino de Física na Amazônia. Revista Ibero-Americana de Educação, n. 50/6, 2009.

MOREIRA, M. A. Mapas conceituais e Aprendizagem significativa. Tradução do artigo Diagramas V y aprendizaje significativo. Publicado na Revista Chilena de Educación Cinentífica, v. 6, p. 1, 2007.

NÓVOA, A. Os professores e sua formação. Lisboa: Dom Quixote, 1992.

POLACZINSKI, A. P. A perspectiva da contextualização dos conteúdos de física em aulas do ensino médio propostas por estagiários de um curso de licenciatura em física. Dissertação (Mestrado em Educação nas Ciências) - Universidade Regional do Noroeste do Estado do Rio Grande do Sul. Ijuí, 2011.

QUIRINO, W. G.; LAVARDA, F. C. Projeto "Experimentos de Física para o Ensino Médio com materiais do dia-a-dia". Caderno Catarinense de Ensino de Física, v. 18, n. 1, p. 117-122, 2001.

RAMOS, E. M. de F; BENETTI, B. Estágio Supervisionado de prática de ensino - espaço pedagógico para conhecimentos tácitos e explícitos. XVIII Simpósio Nacional de Ensino de Física, Vitória, Espírito Santo, 2009.

RODRIGUES, A.; MATTOS, C.; LEOPOLDO, W. O planejamento do estágio supervisionado em física e a experimentação: possibilidades e limitações. In: IX Congreso Internacional sobre Investigación em Didáctica de las Ciencias, 2013, Girona, Espanha.

ROZA, C. F. da. Enfoque CTS no Ensino de Física: Um estudo com estagiários da Licenciatura em Física. Dissertação (Mestrado em Educação) - Universidade Federal do Paraná. Curitiba, 2011.

SILVA, G. S. F. da; VILLANI, A. A dinâmica de um grupo de alunas nas aulas de Física, a sua relação com o saber e as intervenções do professor. Investigações em Ensino de Ciências, v. 17, n. 1, p. 183-208, 2012.

SILVEIRA, T. A. da; LEÃO, M. B. C.; LINS, M. A produção de vídeos digitais como atividade colaborativa na formação inicial de professores de Química. Anais do XIV Encontro Nacional de Ensino de Química. Curitiba, Paraná, 2008.

SCHÖN, D. Formar professores como profissionais reflexivos. In: NÓVOA, A. Os Professores e sua Formação. Lisboa: Dom Quixote, 1992.

SCHWANTES, L.; HECKLER, V.; ARAUJO, R. R.; LEMOS, M. V. Estágio supervisionado em ensino de Física: potencialidades e desafios da docência na escola. In: I Sintec - Seminário Internacional Educação em Ciências, 2011, Rio Grande. I Ebook. Rio Grande: FURG, 2011.

SUASSUNA, L. Pesquisa qualitativa em Educação e Linguagem: histórico e validação do paradigma indiciário. Perspectiva, Florianópolis, v. 26, n. 1, 2008.

ZEICHNER, K. A formação reflexiva de professores: ideias e práticas. Lisboa: Educa, 1993.

\section{NOTAS}

${ }^{1}$ A pesquisa foi autorizada pelo Comitê de Ética da Universidade Estadual de Maringá, com número do parecer 204.813 e também foi autorizada pelo coordenador do Curso de Física, tanto para a participação dos alunos quanto para a do docente como pesquisador. 
Submetido em 08/05/2016

Aprovado em 13/10/2017

Contato:

Ricardo Francisco Pereira (autor principal)

Av. Cerro Azul, no 1499, bloco B, apartamento 501

Jardim Novo Horizonte, Maringá, Paraná

CEP 87.010-055

Endereço da Instituição onde atua:

Universidade Estadual de Maringá

Av. Colombo, $n^{0} 5790$

Jardim Universitário - Maringá, Paraná

CEP 87.020-900 